\title{
HACIA UNA PRÁCTICA TRANSFORMADORA EN TRABAJO SOCIAL: IMPLICACIONES PARA LOS DERECHOS HUMANOS Y SOCIALES [EN] TOWARDS A TRANSFORMATIVE PRACTICE IN SOCIAL WORK: IMPLICATIONS FOR HUMAN AND SOCIAL RIGHTS
}

Feliciano, I. (2019). Hacia una práctica transformadora en Trabajo Social: Implicaciones para los Derechos Humanos y Sociales [Towards a transformative practice in Social Work: Implications for Human and Social Rights]. San Juan: Bibliográficas. 230 pp. ISBN: 978-1-64131-298-1 
Hacia una práctica transformadora en Trabajo Social: Implicaciones para los Derechos Humanos y Sociales (Feliciano, 2019), es una propuesta que invita a romper paradigmas y cuestiona el quehacer profesional del trabajo social interpelándonos a la reflexiónacción. El libro se divide en dos partes. En la primera encontraremos 3 capítulos que abordarán la acción social en el contexto socioeconómico y político. La segunda parte contiene 5 capítulos en los que se esbozan perspectivas y enfoques para repensar la acción profesional.

Desde el prólogo del libro, escrito por la Dra. Raquel Seda-Rodríguez, Presidenta Honoraria del Colegio de Profesionales del Trabajo Social y Profesora Emérita de la Universidad de Puerto Rico, se ubica la transformación como eje central del libro. La Dra. Seda le llama la función de la transformación social. Siempre, cuando se habla de "transformación" en el trabajo social me traslado al análisis de esta palabra que podemos usar sin estar conscientes de sus implicaciones. Castro-Serrano y Frotts (2018) indican que en nuestra profesión y disciplina académica hay un deseo inherente de transformación. Sin embargo, postulan que hay que estar claro qué se quiere transformar.

La Dra. Feliciano presenta magistralmente en su libro la ruta que propone para lo que ella llama una práctica trasnformadora. En ese ideario, se asumen los matices que ya nos habían presentado Martínez y Agüero (2014) llamándola práctica emancipadora caracterizada por ser antipatriarcal, anticapitalista, postcolonial y contrahegemónica. Sin embargo, la profesora Feliciano va más allá. Nos recuerda que la base es la defensa de los derechos humanos desde las políticas sociales. Esto, nos ubica en un marco complejo estructural que nos aleja de lo que Netto (2002) denunciaba como la estrategia del Estado para fragmentar la cuestión social a través de políticas sociales que se desvinculan unas de otras enfatizando en la dimensión privada de esos factores. Para asumir la propuesta que presenta la autora, nos propone que echemos mano de las perspectivas críticas, las antiopresivas, la perspectiva de género, la perspectiva multicultural y la educación popular. Para Feliciano, no se puede transformar siendo agentes de cambio de las personas en función de las estructuras hegemónicas de opresión.

Me parece esencial que Isabel parte de reconocer la política social como esencial a la práctica profesional. Es un asunto de umbral en el libro porque ubica inmediatamente la práctica con un carácter político. Este libro es una buena vacuna contra la proliferación de enfoques asépticos de trabajo social que se basan en acercamientos donde el problema es la persona. La doctora Feliciano 
expresa, "El carácter esencialmente político de la práctica profesional convoca a contextualizar la misma desde la realidad socioeconómica y política actual de cara a las políticas neoliberales y coloniales" (p. 65). Entonces nos llama a cuestionar la política social para que responda a las necesidades de las personas, el llamado a la diversidad, a la utilización de teorías modelos y enfoques críticos, identificar y contrarrestar la opresión, el desarrollo de acciones profesionales que promuevan la solidaridad, la cooperación, la equidad, la justicia, la paz y la libertad. Otros aspectos importantes son el cuestionamiento de los espacios laborales contradictorios, el aprendizaje (que ella llama nutrición) de los saberes y experiencias de las personas y comunidades, la construcción de ciudadanos.

Para la autora, nuestra ética no es abstracta. Por eso, analiza la situación política del país para a base de eso presentar los debates y tensiones del accionar profesional. Uno de ellos es la problematización del concepto tradicional de "intervención social" y la apropiación resignificada del mismo. Para ella, la intervención es un espacio de lucha.

En la segunda fase del libro, nos presenta perspectivas críticas para la acción profesional. El contenido de estos capítulos debe ser incluido en los cursos de intervención en todos los niveles de la formación profesional. Reconoce el uso sostenido de las perspectivas sistémicas y ecológicas para llevarnos a la necesidad de un pensamiento influenciado por las teorías críticas. Para ella, este acercamiento facilita la promoción de cambios sociales, la defensa de los derechos y la articulación de procesos dialécticos, participativos y colectivos. Lo considero necesario porque se aleja de lo individual para primar en el nivel colectivo y nos invita a encarar las estructuras sociales que generan opresiones. Esto, para la autora nos acercará de forma compulsoria a los movimientos sociales. Una frase poderosa del libro son lo que ella llama los elementos potenciadores de una práctica crítica. Estos son la transformación, la emancipación, la liberación y la potenciación de la ciudadanía. Un elemento fundamental es que Isabel no solamente hace uso de su experiencia, investigaciones y su práctica que se ha caracterizado por acciones que son más contundentes que su discurso. En el libro, cita a reconocidos autores críticos y antiopresivos para detallar y mostrarnos las formas en que la práctica del trabajo social nos lleva a trabajar hacia la equidad de las personas oprimidas. Se incluye el análisis de las relaciones de poder que crean las condiciones que le sirven de base a las estructuras de opresión y el cuestionamiento de suposiciones 
y creencias dominantes. Todo esto, para orientar a las personas hacia la emancipación personal y hacia el cambio social.

La propuesta que en este libro se ofrece se aleja de las funciones conservadoras y de control social para asumir un verdadero compromiso con la transformación. El libro asume la dualidad teoría y praxis que en tantas ocasiones asumimos como algo separado y sin relación. Desde una cartografía teórica sólida la autora esboza elementos concretos de la práctica profesional que parten de la concienciación de las condiciones de desigualdad hasta el ejercicio de la desobediencia civil. Sin miedo le podríamos llamar un trabajo social radical. $Y$ es que no hay transformación sin radicalización de ciertas luchas.

La educación popular es presentada como un enfoque que potenciará la capacidad crítica de la persona trabajadora social. La propuesta es incomoda, y no lo postulo como algo negativo. La transformación puede tener efectos incómodos. No hay recetas porque en el trabajo social que ella propone hay un elemento contextual a cada situación. Indica que hay que tener una humildad en el reconocimiento de los saberes. Considero que es un llamado trascendental a una práctica horizontal. En esa práctica que se propone en esta obra es necesario identificar el poder, los privilegios, los prejuicios, el discrimen y los estigmas. En esa búsqueda hay que analizar los niveles estructurales, institucionales e individuales.

Este libro es esencial para todas las personas que hemos abrazado una práctica trasformadora. Sin embargo, pienso que debería ser una lectura obligada para alguna persona que haya pasado por el trabajo social, pero que la disciplina no haya pasado por ella. Hay demasiados intentos para desvirtuar los caminos emancipatorios que Isabel esboza en su libro. En mi caso, como trabajador social con práctica clínica y forense me parece una guía de reflexión de mis quehaceres. Nos ayuda a combatir la tentación que surge en algunas instancias de la formación y práctica clínica que nos lleva a psicologizar el trabajo social de esta dimensión de nuestra práctica. Esto con el objetivo de evitar asumir un ejercicio profesional terapéutico enfocado en la visión médica del diagnóstico y en modelos que ignoran o minimizan las condiciones sociales que cultivan tensión emocional en las relaciones sociales. El libro presenta rutas para asumir una identidad que convierta esta práctica en una antiopresiva y nos lleve a pensar y elaborar modelos emancipatorios que se alejen de la patología. 
En el aspecto forense, mi otra área de trabajo nos ayuda a integrar los elementos transformadores para evitar reproducir las injusticias que ocurren en los escenarios de justicia. De igual forma es una herramienta esencial para ponderar elementos críticos en los análisis forenses. Sin duda, el libro convierte la ética en acción. Invito a su lectura y al análisis en círculos de estudio de las propuestas que se presentan. La doctora Feliciano ha elaborado una ruta que hace visible un trayecto escabroso que tiene mucha niebla en sus rutas, pero que nos debe motivar a caminar al destino posible de la transformación.

\section{Referencias}

Castro-Serrano, B., \& Flotts, M. (2018). Imaginarios de Transformación: El trabajo social revisitado. Santiago: RiL Editores.

Feliciano, I. (2019). Hacia una práctica trasnformadora en Trabajo Social: Implicaciones para la defensa de los derechos humanos y sociales. San Juan: Bibliográficas.

Martínez, S., \& Agüero, J. (2014).

Trabajo Social Emancipador:

De la disciplina a la indisciplina.

Provincia de Entre Ríos: Editorial

Fundación la Hendija.

Netto, J. (2002). Capitalismo

Monopolista y Servicio Social.

Sao Paulo: Cortez Editora. 